\title{
A necessidade de parâmetros referenciais de cortisol em atletas: Uma revisão sistemática
}

\author{
The need for reference parameters of cortisol in athletes: A systematic \\ review
}
Priscilla Bertoldo dos Santos, $1^{*}$ Thais do Amaral Machado, ${ }^{1}$ Ana Cláudia Vecchi Osiecki, ${ }^{2}$ Suelen Meira Góes, ${ }^{1}$ Neiva Leite, ${ }^{1}$ Joice Mara Facco Stefanello ${ }^{1}$

ARTIGO ORIGINAL | ORIGINAL ARTICLE

\begin{abstract}
As concentrações de cortisol constituem uma importante variável de mensuração do estresse, mas existem controvérsias sobre as respostas desse hormônio ao exercício físico, treino e competição. O intuito desta revisão sistemática foi analisar objetivos, metodologias e principais resultados das pesquisas que utilizaram o cortisol como medida de análise do estresse em atletas. Verificou-se a predominância do cortisol salivar $(54.6 \%)$ em várias modalidades desportivas, a maioria foi realizada com modalidades individuais $(72.8 \%)$, com atletas do género masculino $(59 \%)$ e atletas profissionais de alto rendimento (91\%). Diversos procedimentos e momentos de coleta foram descritos nos artigos revisados. As alterações nas concentrações de cortisol salivar detetadas nestes estudos demonstraram que grande parte das situações desportivas foram consideradas possíveis fontes de estresse para atletas. O maior aumento nas concentrações de cortisol foi encontrado entre a situação basal e a situação pós-competitiva, bem como entre as coletas realizadas no dia da competição e aquelas mensuradas no mesmo horário em repouso. A partir da análise dos resultados da presente revisão, percebeu-se a necessidade de uma padronização nos métodos de análise do cortisol em atletas, bem como do controle do ritmo circadiano, a fim de encontrar valores referenciais.

Palavras-chave: cortisol, atletas, estresse
\end{abstract}

ABSTRACT

The cortisol levels are an important variable to measure stress. Yet there is still controversy about these hormone responses to physical exercise, sports training and competition. The purpose of this systematic review was to analyze the objectives, methodological procedures and main results of studies reporting cortisol hormone as a measurement of stress in athletes. There was a predominance of salivary cortisol $(54.6 \%)$ in a wide variety of sports. Most research was conducted in individual sports $(72.8 \%)$, male subjects $(59 \%)$ and high-performance or professional athletes $(91 \%)$. Several procedures and times of collection have been described in the literature. Changes in salivary cortisol level found in this review showed that most sports were considered as a possible source of stress for athletes. The highest increase in cortisol levels was found between baseline and post-competitive situation, as well as between samples taken on the competition day and those measured at the same time at rest. As a conclusion, there is the need to standardize the procedures for cortisol assessment in athletes, as well as the control of circadian rhythm in order to meet the reference values.

Keywords: cortisol, athletes, stress

Artigo recebido a 16.03.2013; $1^{\text {a }}$ Revisão 18.05.2013; Aceite 19.06.2013

${ }^{1}$ Departamento de Educação Física, Universidade Federal do Paraná, Curitiba - PR, Brasil

${ }^{2}$ Faculdade Dom Bosco, Curitiba - PR, Brasil

* Autor correspondente: Departamento de Educação Física da Universidade Federal do Paraná, Rua Coração de Maria, 92, Jardim Botânico, CEP: 80215-370 Curitiba, PR - Brasil; E-mail: pribertoldo@gmail.com 


\section{INTRODUÇÃO}

Atletas de diferentes modalidades e níveis competitivos são constantemente submetidos a um grande número de agentes estressores, cujas reações psicofisiológicas resultam numa resposta específica do sistema nervoso central e do sistema endócrino, particularmente, da glândula suprarrenal (Soares \& Alves, 2006).

Com o aumento nos níveis de estresse, seja de origem psicológica, física ou ambiental, o sistema endócrino é ativado, resultando na maior liberação de hormônios glucocorticoides, sendo o cortisol (hidrocortisona, composto F) o mais importante dentre os glucocorticoides feitos pelo organismo humano, e exercendo a maior parte da atividade metabólica (Wilmore \& Costill, 2001). Como sua produção e secreção aumentam durante e após a exposição a alguns estressores, o cortisol é considerado o hormônio do estresse (Kim, Chung, Park \& Shin, 2009; Soares \& Alves, 2006; Suay et al., 1999).

A produção e secreção desse hormônio varia de acordo com o ciclo circadiano, atingindo picos máximos na segunda metade da manhã, seguidos por sucessíveis declínios durante o dia. Continuamente, alcança valores mínimos no início da noite (períodos noturnos de quiescência) e eleva-se suavemente na segunda metade da noite, após, aproximadamente, 2 horas de iniciado o sono (Hofstra \& De Weerd, 2008). No entanto, ações estressoras e condições lesivas, tais como infeções, traumatismo, calor ou frio intenso, presença de noradrenalina, alterações no sono, horários de alimentação, cirurgias e exercícios físicos, entre outros fatores, podem interferir no ritmo circadiano da secreção do cortisol. Portanto, diante dos mais variados agentes estressores pode haver um aumento repentino nas concentrações de cortisol (Brandão \& Lachat, 1995).

Apesar de as concentrações de cortisol serem uma importante variável de mensuração do estresse em diversos contextos (Soares \& Alves, 2006), ainda existem controvérsias sobre a real resposta desse hormônio ao exercício físico, ao treino e à competição desporti- va. Sabe-se que a continuidade das situações de estresse libera hormônios glucocorticoides (cortisona, cortisol e corticosterona), que em proporções apropriadas estimulam a aprendizagem e a memória, mas, se forem crónicas e em grandes quantidades, diminuem a imunidade do indivíduo, podendo ser prejudiciais à sua saúde (Nahas, 2001).

Estudos têm apontado importantes evidências do cortisol como medida significativa do estresse competitivo e como indicador da síndrome do sobretreino em atletas. Houston (2001) diagnosticou que o cortisol é liberado durante o exercício físico prolongado. Aubets e Segura (1995) observaram que as medidas de cortisol em atletas de alto nível são marcadores simples e sensíveis do estresse competitivo e que mulheres apresentam maiores concentrações de cortisol do que homens. Bullock, Cox, Martin e Marino (2009) verificaram que as concentrações de cortisol salivar e plasmático sofreram alterações em atletas de alta performance durante viagens internacionais, principalmente, em decorrência do fuso horário, que causa alguma dessincronização do relógio biológico do indivíduo. Kim, Chung, Park e Shin (2009), analisando o comportamento do cortisol salivar em golfistas das categorias juniores e profissionais, em repouso, antes, durante e após a competição, constataram que as concentrações de cortisol dos atletas de ambas as categorias foram mais elevadas antes de iniciar a competição. Resultados similares foram também encontrados pelos autores com ciclistas, judocas, maratonistas e atletas de parapente.

Embora vários estudos tenham apontado aumentos nas concentrações de cortisol em decorrência dos mais diversos agentes estressores, muitas questões relacionadas aos níveis de estresse em atletas, quando avaliados por meio do cortisol salivar, sanguíneo ou urinário, requerem maior esclarecimento. Pouco se sabe até que ponto um evento potencialmente estressante pode, de fato, gerar elevados níveis de estresse em atletas, bem como em que medida o desporto competitivo contribui para a transformação e o desenvolvimento do atleta 
ou se constitui num terreno fértil para levá-lo a testar e transcender os seus próprios limites.

Diante dessas lacunas no conhecimento científico, o presente estudo de revisão sistemática se propôs a analisar os objetivos, os procedimentos metodológicos e os principais resultados das pesquisas que utilizaram o cortisol salivar, sanguíneo e urinário como medida de análise do estresse desportivo para atletas de diferentes modalidades, géneros e níveis competitivos.

\section{MÉTODO}

A revisão sistemática é uma forma de pesquisa que utiliza como fonte de dados a literatura sobre determinado tema, disponibilizando um resumo das evidências relacionadas a uma estratégia de intervenção específica, mediante a aplicação de métodos explícitos e sistematizados de busca, apreciação crítica e síntese da informação selecionada. Este tipo de estudo serve para nortear o desenvolvimento de projetos, indicando novos rumos para futuras investigações e identificando quais métodos de pesquisa foram utilizados em uma área (Sampaio \& Mancini, 2007).

A presente revisão seguiu os seguintes procedimentos: Inicialmente, procedeu-se à busca, em inglês e português, dos descritores stress (estresse), cortisol (cortisol) e athletes (atletas), nas bases de dados eletrónicas Lilacs, Medline/Pubmed, Scielo e Science Direct. Essa primeira busca foi efetuada por duas pesquisadoras, entre setembro a dezembro de 2011, de acordo com a metodologia proposta por Sampaio e Mancini (2007), encontrando-se 1780 artigos.

Tendo em vista o avanço científico das pesquisas realizadas na área, delimitou-se a inclusão de artigos originais realizados com humanos, publicados entre 2000 e 2011, para garantir a atualidade dos resultados encontrados, totalizando 632 artigos. Após essa etapa, excluíram-se artigos que não foram realizados com atletas, que não utilizaram o cortisol para avaliação do estresse e que estavam repetidos na mesma base de dados, restando um total de 139 artigos.
$\mathrm{Na}$ sequência, procedeu-se à leitura desses artigos na íntegra e, em uma reunião de consenso, definiram-se critérios de inclusão e exclusão com base na metodologia empregada pelos pesquisadores, obtendo-se 22 artigos. Como critérios de inclusão consideram-se artigos em que o cortisol foi avaliado em situações reais de treino ou competição e artigos em que foram realizadas coletas de cortisol basal e/ou em condição de repouso, para possibilitar o controle do ritmo circadiano dos atletas. Como critério de exclusão estabeleceu-se o uso de suplementação e/ou estímulo ao estresse que pudesse influenciar as concentrações de cortisol. Os procedimentos adotados em cada uma das etapas anteriormente descritas são apresentados na Figura 1.

Os 22 artigos selecionados foram, então, analisados quanto à qualidade metodológica, seguindo um protocolo elaborado para este estudo. Os critérios e a pontuação referentes à qualidade dos artigos foram estabelecidos de forma independente e depois analisados de forma conjunta pelas pesquisadoras. A qualidade dos artigos (Tabela 1) foi verificada a partir dos seguintes critérios: (1) aprovação em comité de ética; (2) metodologia adequada aos objetivos propostos; (3) coletas de cortisol em repouso; (4) coleta de cortisol basal (ao acordar) e (5) coleta de cortisol antes (pré) e após a situação desportiva (treino/competição).

Pelo fato de os estudos analisados terem utilizado diferentes unidades de medida do cortisol (ug/dl, ng/ml, nmol/l), para a análise realizada na presente revisão, todas as medidas foram padronizadas para nmol/l (nanomol por litro), seguindo o valor proposto pelo Manual de Ensaios do ADVIA Centaur e ADVIA Centaur XP (Ensaio Cortisol - Siemens Healthcare Diagnostics) e pelo Manual do Kit DSL-10671000 ACTIVE $^{\circledR}$ Cortisol Enzima Imunoensaio (EIA), sendo considerado $1 \mathrm{ug} / \mathrm{dL}$ ou $1 \mathrm{ng} / \mathrm{ml}=27.6 \mathrm{nmol} / \mathrm{L}$. Após essa padronização (valores corrigidos para $\mathrm{nmol} / \mathrm{l}$ ) foram calculadas as diferenças percentuais nas concentrações de cortisol entre as coletas obtidas nas condições basais/repouso e aquelas aferidas 
Artigos encontrado através dos descritores: estresse (stress), cortisol (cortisol) e atletas (atlhetes)

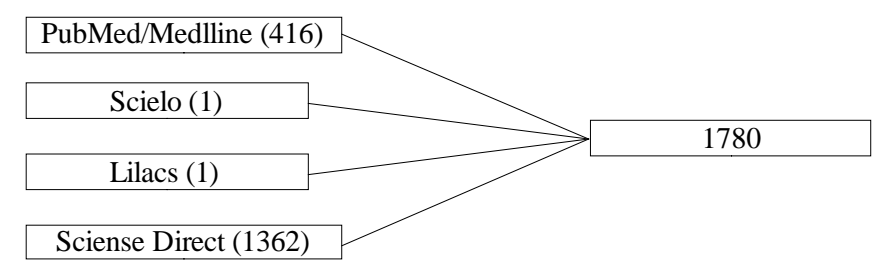

1a. Fase: Fase de Inclusão

\begin{tabular}{|c|c|}
\hline Artigos publicados nos últimos 11 anos de revisão (521) & 1259 \\
\hline Artigos realizados com humanos (85) & 1124 \\
\hline Artigos originais (551) & 632 \\
\hline
\end{tabular}

Critérios de Exclusão

Artigos que não foram feitos com atletas (167)

Artigos que não ultilizaram cortisol na metodologia (269)

\begin{tabular}{|c|}
\hline 456 \\
\hline 187 \\
\hline 139 \\
\hline
\end{tabular}

2a. Fase: Critérios de Inclusão

Artigos que o cortisol foi avaliado no esporte competitivo (53)

\begin{tabular}{|c|}
\hline 56 \\
\hline 57
\end{tabular}

Artigos que utilizaram coleta de cortisol basal e/ou repouso (29)

Critérios de Exclusão

Artigos que utilizaram algum tipo de suplementação (35)

Figura 1. Etapas da revisão sistemática

nas situações de treino e/ou competição, a fim de viabilizar a análise dos resultados.

\section{RESULTADOS}

Primeiramente são apresentados os objetivos e a metodologia dos estudos selecionados e, posteriormente, seus principais resultados.

\section{Objetivos e metodologia dos estudos}

Do total de artigos analisados, $40.9 \%$ realizaram coletas durante o período de treino,
$36.4 \%$ em período de competição, $18.2 \%$ em períodos de treino e competição e $4.5 \%$ em período pré-competitivo e competitivo.

Considerando os objetivos propostos, $31.8 \%$ dos estudos procuraram analisar os efeitos da competição sobre as concentrações de cortisol; $45.5 \%$, os efeitos das cargas de treino sobre os níveis de cortisol dos atletas durante as temporadas desportivas; $18.2 \%$, as respostas psicológicas e fisiológicas antecipatórias do cortisol em relação à competição e ao 
treino; e $4.5 \%$, os efeitos longitudinais do treino físico intenso sobre a capacidade antioxidante e os danos lipoperoxidativo e muscular nos atletas.

De acordo com a classificação etária proposta por Havighurst e Levine (1979), observa-se que $59 \%$ contemplou adultos jovens (19 a 29 anos); $4.5 \%$ adolescentes, adultos jovens e médios (12 a 60 anos); $13.6 \%$ adolescentes (entre 13 a 18 anos) e $22.7 \%$ adultos jovens e médios (19 e 60 anos). Quanto ao género, 59\% contemplaram atletas masculinos, $13.7 \%$, atletas femininos e $23.3 \%$, ambos.

No que se refere às modalidades, $72.8 \%$ dos estudos foram conduzidos com modalidades individuais, $22.7 \%$ com modalidades coletivas e $4.5 \%$ não informaram. Em $91 \%$ dos estudos, os atletas eram profissionais de alto rendimento e em $9 \%$, adolescentes que competiam em nível inter-regional.

Quanto aos procedimentos, a maioria dos estudos (54.6\%) adotou o cortisol salivar para avaliar os níveis de stress dos atletas. Em relação aos momentos das coletas, observou-se que somente $13.6 \%$ estudos procuraram comparar as concentrações de cortisol na condição basal (ao acordar) ou em condições de repouso com os valores obtidos na competição (análises em repouso no mesmo horário das competições). Nos estudos em que foram acompanhados temporadas/campeonatos desportivos, somente $13.6 \%$ realizaram apenas coletas em repouso (sempre no mesmo horário). Quando investigados os efeitos do treino $(31.8 \%$ dos estudos), foram comparadas as concentrações de cortisol basal antes e após o período de treino $(13.6 \%)$ e em apenas em $9.1 \%$ dos estudos revisados foram analisadas as respostas antecipatórias do cortisol à competição. Os poucos estudos que utilizaram o cortisol urinário ( $9.1 \%$ dos estudos revisados) monitoraram as concentrações de cortisol durante 24 horas, com o objetivo de comparar as medidas de repouso com diferentes momentos de uma temporada de treino ou para analisar as variações nas concentrações de cortisol nos dias de competição.

\section{Principais resultados encontrados nos estu- dos revisados}

Apenas os resultados referentes às concentrações de cortisol que apresentaram significância estatística foram analisados, o que correspondeu a $75 \%$ dos artigos avaliados (Tabelas 3 , 4 e 5 ).

De forma geral, dentre os estudos que compararam concentrações de cortisol em repouso/basal com aquelas encontradas em situações desportivas (treino, competição), 68.2\% tiveram alterações significativas. Destes, $9.1 \%$ demonstraram diminuição nas concentrações de cortisol em situações desportivas, enquanto $59.1 \%$ encontraram aumentos nas concentrações de cortisol, quando comparadas com as coletas basais.

As Tabelas 3, 4 e 5 apresentam, respetivamente, as diferenças percentuais encontradas nas concentrações de cortisol salivar, sanguíneo e urinário, calculadas a partir dos resultados dos estudos revisados.

Os valores de cortisol encontrados em situações desportivas foram comparados com as coletas basais/repouso em $27.7 \%$ dos artigos (Coutts, Wallace, \& Slattery, 2007; Filaire, Sangnol, Ferrand, Maso, \& Lac, 2001; Garcia et al., 2002; Georgopoulos et al., 2011; Minetto et al., 2008; Salvador, Ricarte, González-Bono, \& Moya-Albiol, 2001). As concentrações de cortisol em condições de repouso fora da situação competitiva e de repouso em situação competitiva foram analisadas em $36.5 \%$ dos estudos (Filaire et al, 2001; Filaire, Alix, Ferrand \& Verger, 2009; Filaire, Portier, Onen, \& Filaire, 2010; Kivlighan, Granger, \& Booth, 2005; Maso et al., 2002; Salvador, Suay, GonzálezBono, \& Serrano, 2003; Strahler, Ehrlenspiel, Heene, \& Ralf, 2010; Teixeira et al., 2009). Análises basais em diferentes momentos de treino (em vários dias da temporada de treino) foram encontradas em $27.7 \%$ dos estudos (Bought, Rouveix, Michaux, Pequignot \& Filaire, 2006; Coutts et al., 2007; Garcia et al., 2002; Maestu, Jurimae, \& Jurimae, 2003; Maso, Lac, Michaux \& Robert, 2003; Silva, Papoti, Santhiago, Pauli \& Gobatto, 2011). 
Tabela 1

Qualidade metodológica dos artigos selecionados

$$
\text { Artigos }
$$

$\begin{array}{llllll}1 & 2 & 3 & 4 & 5 & \text { Total }\end{array}$

Anticipatory cortisol, testosterone and psychological responses to judo competition in young men (Salvador et al., 2003)

Antioxidant status, oxidative stress, and damage in elite kayakers after 1 year of training and competition in 2 seasons (Teixeira et al., 2009)

Changes in stress and recovery after heavy training in rowers (Jurimae et al., 2004)

Changes in awakening cortisol response and midnight salivary cortisol are sensitive markers of strenuous training-induced fatigue (Minetto et al., 2008)

Competitive anxiety and cortisol awakening response in the week leading up to a competition (Strahler et al., 2010)

Corrélations entre scores au questionnaire de la Société française de médecine du sport et concentrations de cortisol et testostérone salivaires lors du suivi d'une équipe de rugby de haut niveau (Maso et al., 2003)

Effects of physical training on endocrine and autonomic response to acute stress (Salvador et al., 2001)

Gender differences in testosterone and cortisol response to competition (Kivlighan et al., 2005)

Hormonal reactions during heavy training stress and following tapering in highly trained male rowers (Maestu et al., 2003)

Influence d'une compétition de rugby sur le taux de cortisol salivaire (Maso et al., 2002)

Monitoring changes in performance, physiology, biochemistry, and psychology during overreaching and recovery in triathletes (Coutts et al., 2007)

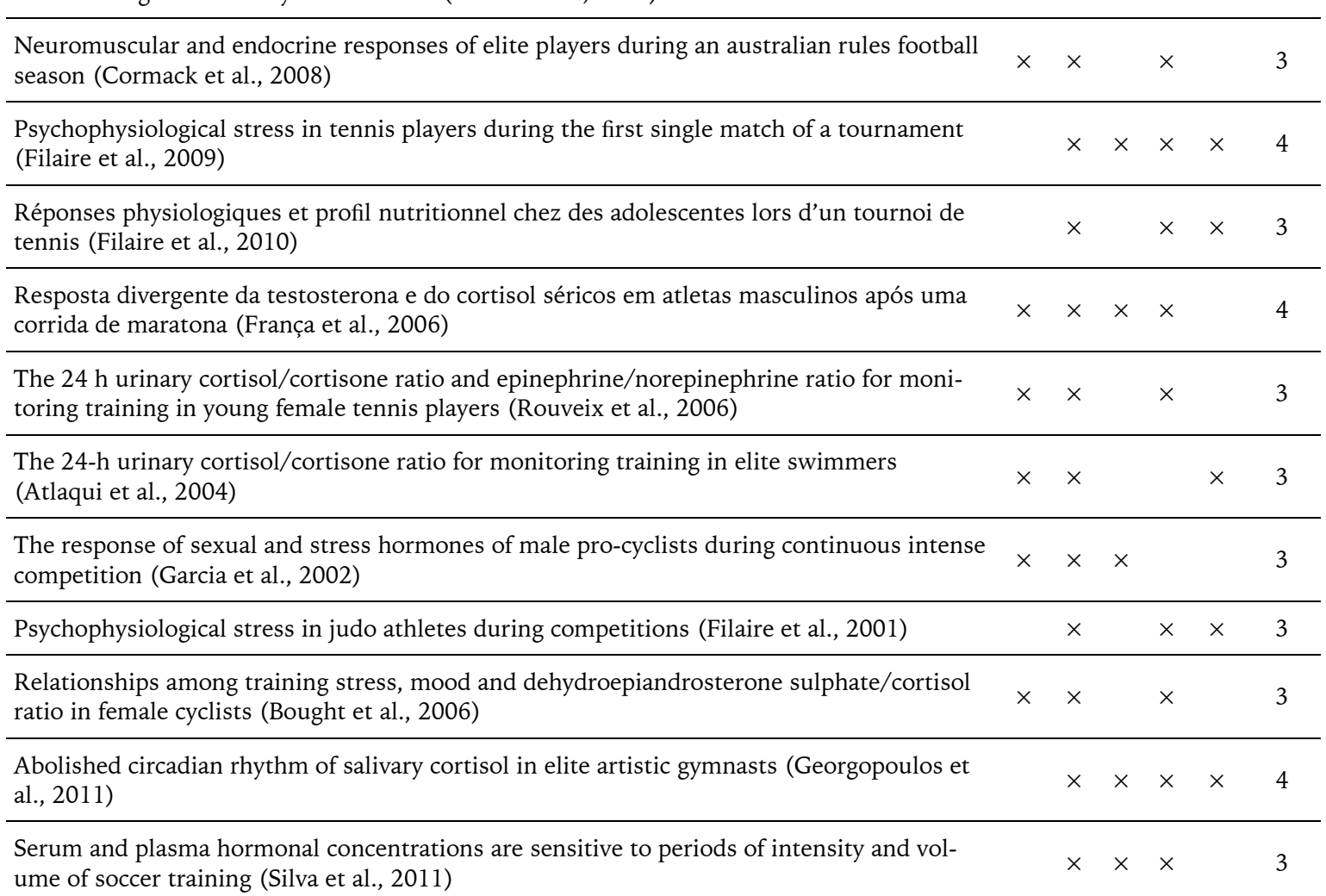
ume of soccer training (Silva et al., 2011)

Nota: * artigos que obtiveram a pontuação máxima (cinco pontos) em relação aos critérios de qualidade 
Tabela 2

Objetivos e metodologia dos artigos revisados

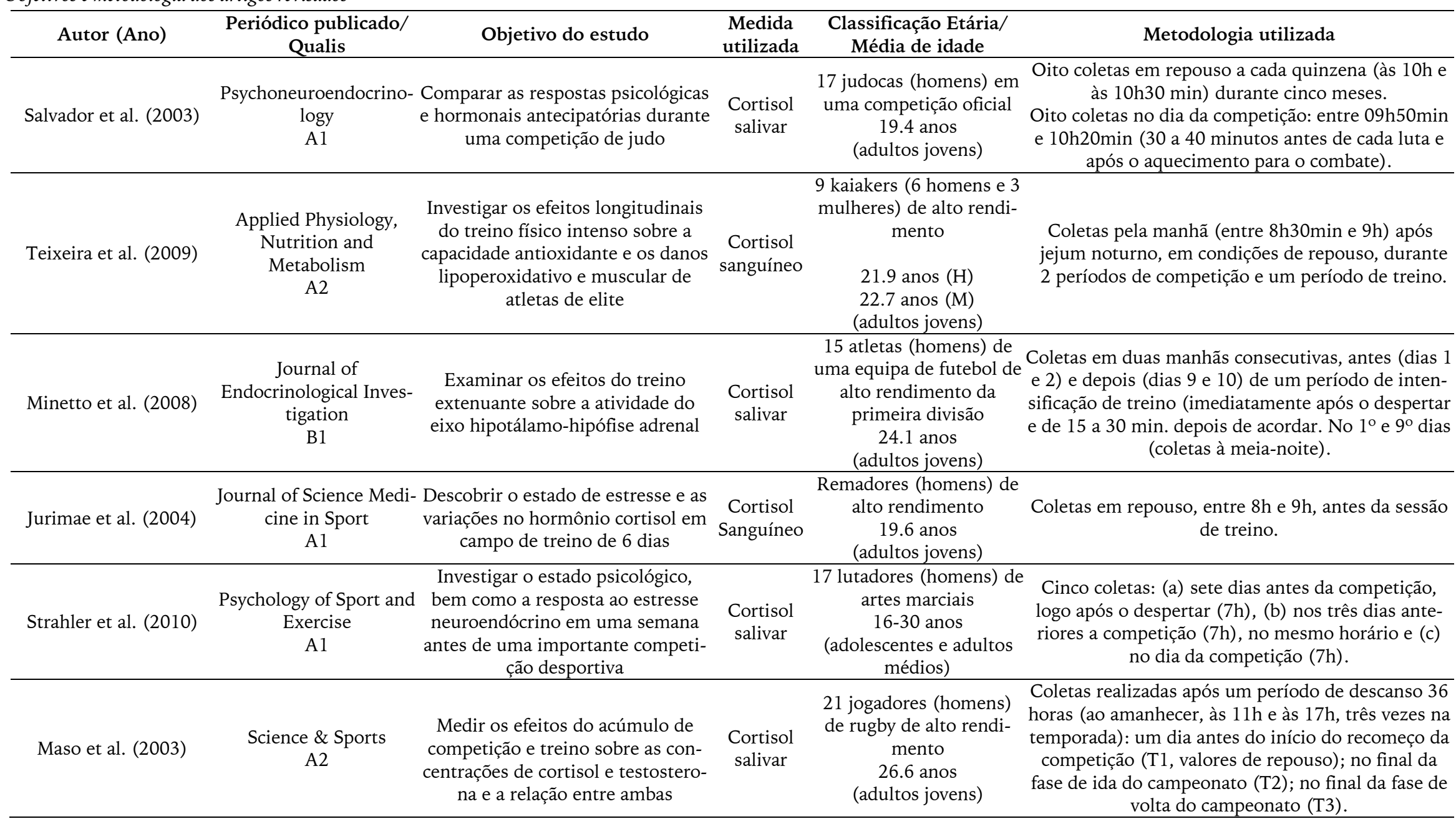


Tabela 2 (continuação)

Objetivos e metodologia dos artigos revisados

\begin{tabular}{|c|c|c|c|c|c|}
\hline Autor (Ano) & $\begin{array}{c}\text { Periódico publicado/ } \\
\text { Qualis }\end{array}$ & Objetivo do estudo & $\begin{array}{c}\text { Medida } \\
\text { utilizada }\end{array}$ & $\begin{array}{l}\text { Classificação Etária/ } \\
\text { Média de idade }\end{array}$ & Metodologia utilizada \\
\hline Salvador et al. (2001) & $\begin{array}{l}\text { Journal of Psychophysio- } \\
\text { logy } \\
\text { A2 }\end{array}$ & $\begin{array}{l}\text { Investigar a influência de um fator } \\
\text { de estresse físico crónico, definido } \\
\text { por treino desportivo, na resposta } \\
\text { ao estresse em homens e mulheres }\end{array}$ & $\begin{array}{l}\text { Cortisol } \\
\text { sanguíneo }\end{array}$ & $\begin{array}{l}18 \text { jovens atletas } \\
10 \text { homens e } 8 \text { mulheres } \\
\text { de alto rendimento } \\
20.4 \text { anos }(\mathrm{H}) \\
20.0 \text { anos }(\mathrm{M}) \\
\text { (adultos jovens) }\end{array}$ & $\begin{array}{l}\text { Coletas entre } 9 \mathrm{~h} \text { e } 9 \mathrm{~h} 30 \mathrm{~min} \text {. Uma no início da } \\
\text { temporada de treino e outra } 5 \text { meses depois. }\end{array}$ \\
\hline Kivlighan et al. (2005) & $\begin{array}{c}\text { Psychoneuroendocrino- } \\
\text { logy } \\
\text { A1 }\end{array}$ & $\begin{array}{l}\text { Analisar a mudança intraindividual } \\
\text { de testosterona e cortisol, bem } \\
\text { como o comportamento hormonal } \\
\text { em resposta a uma competição de } \\
\text { remo }\end{array}$ & $\begin{array}{l}\text { Cortisol } \\
\text { salivar }\end{array}$ & $\begin{array}{l}46 \text { remadores (amadores } \\
\text { e alto rendimento) } \\
23 \text { homens e } 23 \text { mulheres } \\
\quad 17-31 \text { anos } \\
\text { (adultos jovens e médios) }\end{array}$ & $\begin{array}{l}\text { Cinco coletas: (a) } 20 \text { minutos antes do aquecimen- } \\
\text { to; (b) } 40 \text { minutos após a competição; (c) Três } \\
\text { amostras "base" nos mesmos horários da competi- } \\
\text { ção. }\end{array}$ \\
\hline Maestu et al. (2003) & $\begin{array}{l}\text { Hormone and Metabolic } \\
\text { Research } \\
\text { B1 }\end{array}$ & $\begin{array}{l}\text { Determinar se concentrações de } \\
\text { leptina plasmática em jejum, corti- } \\
\text { sol, testosterona e hormônio do } \\
\text { crescimento alteram-se com forte } \\
\text { aumento no esforço de treino, } \\
\text { seguido por redução do esforço em } \\
\text { remadores do sexo masculino }\end{array}$ & $\begin{array}{l}\text { Cortisol } \\
\text { sanguíneo }\end{array}$ & $\begin{array}{l}12 \text { remadores (homens) } \\
\text { de alto rendimento } \\
20.5 \text { anos } \\
\text { (adultos jovens e médios) }\end{array}$ & $\begin{array}{l}\text { Coletas às } 9 \mathrm{~h} \text { em cada terça-feira após o dia de } \\
\text { descanso em três diferentes períodos em jejum. }\end{array}$ \\
\hline Maso et al. (2002) & $\begin{array}{l}\text { Science \& Sports } \\
\text { B1 }\end{array}$ & $\begin{array}{l}\text { Mensurar o impacto da competição } \\
\text { desportiva sobre a concentração de } \\
\text { cortisol salivar durante um jogo de } \\
\text { rugby internacional }\end{array}$ & $\begin{array}{l}\text { Cortisol } \\
\text { salivar }\end{array}$ & $\begin{array}{l}20 \text { jogadores (homens) } \\
\text { de rugby de alto rendi- } \\
\text { mento } \\
26.8 \text { anos } \\
\text { (adultos jovens) }\end{array}$ & $\begin{array}{l}\text { Coletas no dia da competição: às } 15 \mathrm{~h} \text { (uma hora } \\
\text { antes do jogo) e às } 18 \mathrm{~h} \text {, (imediatamente após o final } \\
\text { do jogo). Duas coletas em um dia de repouso nos } \\
\text { mesmos horários. }\end{array}$ \\
\hline Coutts et al. (2007) & $\begin{array}{l}\text { International Journal } \\
\text { of Sports Medicine } \\
\text { A1 }\end{array}$ & $\begin{array}{l}\text { Comparar as respostas fisiológicas, } \\
\text { bioquímicas e marcadores psicoló- } \\
\text { gicos de overreaching em triatletas }\end{array}$ & $\begin{array}{l}\text { Cortisol } \\
\text { sanguíneo }\end{array}$ & $\begin{array}{l}16 \text { triatletas (homens) de } \\
\text { alto rendimento } \\
\quad 31.3 \text { anos } \\
\text { (adultos jovens e médios) }\end{array}$ & $\begin{array}{l}\text { Todas as amostras foram coletadas em jejum (entre } \\
6 \text { h30min e } 8 \text { h30min). } \\
\text { As medidas foram tomadas no início, após quatro } \\
\text { semanas de treino com sobrecarga e na sequência } \\
\text { de uma diminuição da sobrecarga de duas semanas. }\end{array}$ \\
\hline Cormack et al. (2008) & $\begin{array}{l}\text { International Journal of } \\
\text { Sports Physiology and } \\
\text { Performance } \\
\text { B1 }\end{array}$ & $\begin{array}{l}\text { Analisar as variações do estado } \\
\text { neuromuscular e hormonal e suas } \\
\text { relações com o desempenho ao } \\
\text { longo de uma temporada de futebol }\end{array}$ & $\begin{array}{l}\text { Cortisol } \\
\text { salivar }\end{array}$ & $\begin{array}{l}15 \text { jogadores de futebol } \\
\text { (homens) de alto rendi- } \\
\text { mento } \\
24.9 \text { anos } \\
\text { (adultos jovens) }\end{array}$ & $\begin{array}{l}\text { Dados de base foram coletados num estado de } \\
\text { repouso ( } 36 \text { horas antes do primeiro jogo da tempo- } \\
\text { rada) e em } 20 \text { ocasiões ao longo da temporada. }\end{array}$ \\
\hline
\end{tabular}


Tabela 2 (continuação)

Objetivos e metodologia dos artigos revisados

\begin{tabular}{|c|c|c|c|c|c|}
\hline Autor (Ano) & $\begin{array}{c}\text { Periódico publicado/ } \\
\text { Qualis }\end{array}$ & Objetivo do estudo & $\begin{array}{c}\text { Medida } \\
\text { utilizada }\end{array}$ & $\begin{array}{l}\text { Classificação Etária/ } \\
\text { Média de idade }\end{array}$ & Metodologia utilizada \\
\hline Filaire et al. (2009) & $\begin{array}{l}\text { Psychoneuroendo- } \\
\text { crinology } \\
\text { A1 }\end{array}$ & $\begin{array}{l}\text { Avaliar as respostas fisiológicas e } \\
\text { os estados psicológicos dos atletas } \\
\text { durante um torneio de ténis }\end{array}$ & $\begin{array}{l}\text { Cortisol } \\
\text { salivar }\end{array}$ & $\begin{array}{l}16 \text { tenistas ( } 8 \text { homens e } 8 \\
\text { mulheres) em torneio } \\
\text { regional } \\
22.2 \text { anos }(\mathrm{M}) \\
20.2 \text { anos }(\mathrm{F}) \\
\text { (adultos jovens) }\end{array}$ & $\begin{array}{l}\text { Duas coletas em um dia de repouso ( } 24 \mathrm{~h} \text { sem trei- } \\
\text { no), às } 8 \mathrm{~h} 30 \mathrm{~min} \text { após o despertar e às } 20 \mathrm{~h} \text {. Seis } \\
\text { coletas no dia do torneio: } 30 \text { min. depois de acordar } \\
\text { (8h); uma hora antes da partida (15h); } 10 \text { min. } \\
\text { antes da partida; } 10 \text { min. depois da partida; uma } \\
\text { hora após o final do jogo e à noite (às } 20 \mathrm{~h}) \text {. }\end{array}$ \\
\hline Filaire et al. (2010) & $\begin{array}{l}\text { Science \& Sports } \\
\text { A2 }\end{array}$ & $\begin{array}{l}\text { Examinar os valores da concentra- } \\
\text { ção de cortisol salivar induzidos } \\
\text { por uma partida de ténis num } \\
\text { torneio }\end{array}$ & $\begin{array}{l}\text { Cortisol } \\
\text { salivar }\end{array}$ & $\begin{array}{l}10 \text { tenistas (mulheres) } \\
\text { Campeonato Inter- } \\
\text { Regional } \\
14.7 \text { anos } \\
\text { (adolescentes) }\end{array}$ & $\begin{array}{l}\text { Coletas durante o dia de jogo: meia hora após o } \\
\text { nascer do sol ( } 7 \mathrm{~h}) \text {; dez minutos antes e dez minutos } \\
\text { depois do jogo ( } 9 \mathrm{~h}, 10 \mathrm{~h} 30 \mathrm{~min}) \text { e às } 20 \mathrm{~h} \text {. Em repou- } \\
\text { so ( } 48 \mathrm{~h} \text { sem praticar qualquer exercício): meia hora } \\
\text { após o nascer do sol (7h) e às } 20 \mathrm{~h} \text {. }\end{array}$ \\
\hline França et al. (2006) & $\begin{array}{l}\text { Arquivos Brasileiros de } \\
\text { Endocrinologia e Meta- } \\
\text { bologia } \\
\text { B1 }\end{array}$ & $\begin{array}{l}\text { Descobrir a resposta divergente da } \\
\text { testosterona e do cortisol séricos } \\
\text { em atletas masculinos após uma } \\
\text { corrida de maratona }\end{array}$ & $\begin{array}{l}\text { Cortisol } \\
\text { sanguíneo }\end{array}$ & $\begin{array}{c}20 \text { maratonistas } \\
\text { (homens) } \\
25-40 \text { anos } \\
\text { (adultos jovens e médios) }\end{array}$ & $\begin{array}{l}\text { Três coletas: (a) } 48 \mathrm{~h} \text { antes da prova, entre } 7 \mathrm{~h} 30 \mathrm{~min} \\
\text { e } 8 \mathrm{~h} 30 \mathrm{~min} \text { da manhã, após } 30 \text { min. de repouso, com } \\
\text { os atletas em jejum de } 12 \mathrm{~h} \text { (controle). (b) no dia da } \\
\text { maratona, logo após o término da corrida (por volta } \\
\text { das } 12 \mathrm{~h} \text { ) (final). (c) no dia seguinte, } 20 \mathrm{~h} \text { após o } \\
\text { término da prova. }\end{array}$ \\
\hline Rouveix et al. (2006) & $\begin{array}{l}\text { International Journal } \\
\text { of Sports Medicine } \\
\text { A1 }\end{array}$ & $\begin{array}{l}\text { Investigar o efeito das variações de } \\
\text { treino sobre o cortisol urinário de } \\
24 \mathrm{~h} \text { e a cortisona (C / Cn), e a } \\
\text { relação epinefrina norepinefrina em } \\
\text { relação com o humor (Escala } \\
\text { BRUMS) e o desempenho }\end{array}$ & $\begin{array}{l}\text { Cortisol } \\
\text { urinário }\end{array}$ & $\begin{array}{l}7 \text { jovens tenistas (mulhe- } \\
\text { res) de alto rendimento } \\
12.8 \text { anos } \\
\text { (adolescentes) }\end{array}$ & $\begin{array}{l}\text { Coletas depois de } 30 \text { horas de recuperação sem } \\
\text { atividade física, em três momentos: após } 1 \text { mês } \\
\text { (repouso, T1), três meses depois de T1 (após técni- } \\
\text { ca de resistência de treino, T2) e } 7 \text { meses após T1 } \\
\text { (após } 4 \text { meses de treino, T3). }\end{array}$ \\
\hline Atlaqui et al. (2003) & $\begin{array}{l}\text { Medicine and Science in } \\
\text { Sports and Exercise } \\
\text { A1 }\end{array}$ & $\begin{array}{c}\text { Analisar o efeito das variações na } \\
\text { relação cortisol urinário/ cortisona } \\
\text { (C / Cn) no período de } 24 \mathrm{~h} \text { no dia } \\
\text { de treino de nadadores altamente } \\
\text { treinados }\end{array}$ & $\begin{array}{l}\text { Cortisol } \\
\text { urinário }\end{array}$ & $\begin{array}{l}14 \text { nadadores de elite }(5 \\
\text { mulheres e } 9 \text { homens) de } \\
\text { alto rendimento } \\
21 \text { anos }(\mathrm{F}) \\
23 \text { anos }(\mathrm{M}) \\
\text { (adultos jovens) }\end{array}$ & $\begin{array}{l}\text { Durante três dias de competição: ao final de } 4 \\
\text { semanas de treino intenso (TI), } 3 \text { semanas de treino } \\
\text { reduzido (PR) e } 5 \text { semanas de treino moderado } \\
\text { (MT). Todas ao longo de um período de } 24 \mathrm{~h} \text {. }\end{array}$ \\
\hline Garcia et al. (2002) & $\begin{array}{l}\text { International Journal } \\
\text { of Sports Medicine } \\
\text { A1 }\end{array}$ & $\begin{array}{l}\text { Comparar as alterações nos níveis } \\
\text { de testosterona total (T), cortisol } \\
\text { (C), hormônio luteinizante (LH), } \\
\text { hormônio folículo estimulante } \\
\text { (FSH) e prolactina (P) em duas } \\
\text { equipes de classe mundial }\end{array}$ & $\begin{array}{l}\text { Cortisol } \\
\text { sanguíneo }\end{array}$ & $\begin{array}{l}18 \text { ciclistas (homens) de } \\
\text { alto rendimento } \\
28 \text { anos } \\
\text { (adultos jovens e médios) }\end{array}$ & $\begin{array}{l}\text { Quatro coletas: um dia antes da competição; no } \\
\text { final da } 1^{\mathrm{a}} \text { semana; no final da } 2^{\mathrm{a}} \text { semana e na } 3^{\mathrm{a}} \\
\text { semana. Todas entre as } 7 \mathrm{~h} \text { e as } 9 \mathrm{~h} \text { da manhã após } \\
\text { uma noite de jejum. }\end{array}$ \\
\hline
\end{tabular}


Tabela 2 (continuação)

Objetivos e metodologia dos artigos revisados

\begin{tabular}{|c|c|c|c|c|c|}
\hline Autor (Ano) & $\begin{array}{c}\text { Periódico publicado/ } \\
\text { Qualis }\end{array}$ & Objetivo do estudo & $\begin{array}{c}\text { Medida } \\
\text { utilizada }\end{array}$ & $\begin{array}{l}\text { Classificação Etária/ } \\
\text { Média de idade }\end{array}$ & Metodologia utilizada \\
\hline Filaire et al. (2001) & $\begin{array}{l}\text { Journal of Sports } \\
\text { Medicine and Physical } \\
\text { Fitness } \\
\text { A2 }\end{array}$ & $\begin{array}{l}\text { Investigar e comparar respostas } \\
\text { psicofisiológicas e psicológicas }\end{array}$ & $\begin{array}{l}\text { Cortisol } \\
\text { salivar }\end{array}$ & $\begin{array}{l}12 \text { judocas (homens) } \\
\text { regional e inter regional } \\
22.2 \text { anos } \\
\text { (adultos jovens) }\end{array}$ & $\begin{array}{l}\text { Três coletas em um dia de repouso, três semanas } \\
\text { antes da primeira competição: ao acordar ( } 8 \mathrm{~h}) \text {, às } \\
12 \mathrm{~h} \text {, e às } 17 \mathrm{~h} \text {. Três coletas no dia de cada competi- } \\
\text { ção: ao acordar (8h), } 5 \text { min antes da primeira luta e } \\
5 \text { min após a última luta. }\end{array}$ \\
\hline Bought et al. (2006) & $\begin{array}{l}\text { Journal of Sports } \\
\text { Sciences } \\
\text { A1 }\end{array}$ & $\begin{array}{l}\text { Analisar o efeito do aumento do } \\
\text { volume e da intensidade de treino } \\
\text { sobre as respostas hormonais }\end{array}$ & $\begin{array}{l}\text { Cortisol } \\
\text { salivar }\end{array}$ & $\begin{array}{l}12 \text { ciclistas (mulheres) de } \\
\text { alto rendimento } \\
21.7 \text { anos } \\
\text { (adultos jovens) } \\
\end{array}$ & $\begin{array}{l}\text { Imediatamente depois de acordar, (entre às } \\
\text { 7h30min e } 8 \mathrm{~h} \text { ) e em } 2 \text { momentos (T1 e T2). }\end{array}$ \\
\hline $\begin{array}{l}\text { Georgopoulos et al } \\
\text { (2011) }\end{array}$ & $\begin{array}{l}\text { Steroids } \\
\text { B1 }\end{array}$ & $\begin{array}{l}\text { Avaliar como os efeitos do exercí- } \\
\text { cio físico intenso e estresse psico- } \\
\text { lógico durante a competição podem } \\
\text { refletir sobre os níveis de cortisol } \\
\text { em ginastas de elite }\end{array}$ & $\begin{array}{l}\text { Cortisol } \\
\text { salivar }\end{array}$ & $\begin{array}{c}239 \text { ginastas de elite } \\
\text { (142 mulheres e } 97 \\
\text { homens) } \\
16 \text { anos } \\
\text { (adolescentes) }\end{array}$ & $\begin{array}{l}\text { Pela manhã (entre } 8 \mathrm{~h} \text { e } 10 \mathrm{~h} \text { ) e à tarde após treino } \\
\text { (entre } 18 \mathrm{~h} \text { e } 20 \mathrm{~h} \text { ) em semana de treino. } \\
\text { Pela manhã em semana escolar (entre } 8 \mathrm{~h} \text { e } 10 \mathrm{~h} \text { ) }\end{array}$ \\
\hline $\begin{array}{l}\text { Silva et al } \\
\quad(2011)\end{array}$ & $\begin{array}{l}\text { Science \& Sports } \\
\quad \text { A2 }\end{array}$ & $\begin{array}{l}\text { Investigar efeitos de } 12 \text { semanas de } \\
\text { um programa de treino sobre as } \\
\text { concentrações hormonais e per- } \\
\text { formance fisiológica de jogadores } \\
\text { de futebol } \\
\end{array}$ & $\begin{array}{l}\text { Cortisol } \\
\text { sanguíneo }\end{array}$ & $\begin{array}{l}18 \text { jogadores de futebol } \\
\text { profissional (homens) } \\
22.2 \text { anos } \\
\text { (adultos jovens) }\end{array}$ & $\begin{array}{l}\text { Três coletas durante o estudo, entre } 8 \mathrm{~h} \text { e } 10 \mathrm{~h} \\
\text { T1 antes do início do programa de treino } \\
\text { T2 (sexta semana) } \\
\text { T3 após } 12 \text { semanas de treino }\end{array}$ \\
\hline
\end{tabular}


Tabela 3

Diferenças percentuais nas concentrações de cortisol salivar encontradas para atletas

\begin{tabular}{|c|c|c|c|}
\hline Artigos & Valores médios encontrados & Valores médios encontrados (nmol/l) & $\begin{array}{l}\text { Diferença percentual nas concentrações } \\
\text { de cortisol salivar }\end{array}$ \\
\hline \multirow{2}{*}{$\begin{array}{l}\text { Minetto et al. } \\
\quad(2008)\end{array}$} & Basal pré-treino: $12.4 \mathrm{nmol} / 1$ & Basal pré-treino: $12.4 \mathrm{nmol} / 1$ & \multirow{2}{*}{$\uparrow 32 \%$ pós-treino } \\
\hline & Basal pós-treino: $16.4 \mathrm{nmol} / \mathrm{l}$ & Basal pós-treino: $16.4 \mathrm{nmol} / \mathrm{l}$ & \\
\hline \multirow{7}{*}{$\begin{array}{l}\text { Kivlighan et al. } \\
\qquad(2005)\end{array}$} & Valores de repouso & Valores de repouso & \multirow{4}{*}{$\begin{array}{c}\text { Homens: } \uparrow 160 \% \text { pré-competição } \\
\text { (Veteranos }=135 \% \text {; Novatos }=186 \%)\end{array}$} \\
\hline & $\begin{array}{l}\text { Homens Veteranos: } 0.23 \mathrm{ug} / \mathrm{dl} / \\
\text { Novatos: } 0.26 \mathrm{ug} / \mathrm{dl}\end{array}$ & $\begin{array}{c}\text { Homens Veteranos }(6.3 \mathrm{nmol} / \mathrm{l}) / \\
\text { Novatos }(7.2 \mathrm{nmol} / \mathrm{l})\end{array}$ & \\
\hline & Mulheres: Veteranas $0.37 \mathrm{ug} / \mathrm{dl} /$ & Mulheres Veteranas $(10.2 \mathrm{nmol} / \mathrm{l}) /$ & \\
\hline & Novatas: 0.J4 ug/ ul & & \\
\hline & Pré-competição & Pré-competição & \multirow{3}{*}{$\begin{array}{c}\text { Mulheres: } \uparrow 163 \% \text { pré-competição } \\
\text { (Veteranas }=94 \% \text {; Novatas }=232 \% \text { ). }\end{array}$} \\
\hline & $\begin{array}{c}\text { Homens Veteranos: } 0.54 \mathrm{ug} / \mathrm{dl} / \\
\text { Novatos: } 0.75 \mathrm{ug} / \mathrm{dl}\end{array}$ & $\begin{array}{c}\text { Homens: Veteranos }(14.8 \mathrm{nmol} / \mathrm{l}) / \\
\text { Novatos }(20.6 \mathrm{nmol} / \mathrm{l})\end{array}$ & \\
\hline & $\begin{array}{l}\text { Mulheres: Veteranas: } 0.72 \mathrm{ug} / \mathrm{dl} / \\
\text { Novatas: } 1.12 \mathrm{ug} / \mathrm{dl}\end{array}$ & $\begin{array}{l}\text { Mulheres Veteranas }(19.8 \mathrm{nmol} / \mathrm{l}) / \\
\text { Novatas }(30.9 \mathrm{nmol} / \mathrm{l})\end{array}$ & \\
\hline \multirow{3}{*}{ Maso et al. (2002) } & Repouso às 15:00h: $4.9 \mathrm{nmol} / \mathrm{l}$ & Repouso às 15:00h: $4.9 \mathrm{nmol} / \mathrm{l}$ & \multirow{2}{*}{ Pré-competição: $\uparrow 73 \%$} \\
\hline & Repouso às 18:00h: $5.6 \mathrm{nmol} / \mathrm{l}$ & Repouso às 18:00h: $5.6 \mathrm{nmol} / \mathrm{l}$ & \\
\hline & $\begin{array}{l}\text { Antes do jogo: } 8.5 \mathrm{nmol} / \mathrm{l} / \\
\text { Após o jogo: } 15.7 \mathrm{nmo} / 1\end{array}$ & $\begin{array}{c}\text { Antes do jogo: } 8.5 \mathrm{nmol} / 1 / \\
\text { Após o jogo: } 15.7 \mathrm{nmo} / 1 \\
\end{array}$ & Pós-competição: $\uparrow 180 \%$ \\
\hline \multirow{4}{*}{$\begin{array}{l}\text { Filaire et al. } \\
\quad(2009)\end{array}$} & Repouso: & Repouso: & \multirow{4}{*}{$\begin{array}{c}\text { Competição: } \uparrow 70 \% \\
\text { Homens ( } \uparrow 51 \%) ; \text { Mulheres ( } \uparrow 89 \%)\end{array}$} \\
\hline & Homens: $14.6 \mathrm{nmol} / \mathrm{l} /$ Mulheres: $15.3 \mathrm{nmol} / \mathrm{l}$ & Homens $(14.6 \mathrm{nmol} / \mathrm{l}) /$ Mulheres $(15.3 \mathrm{nmol} / \mathrm{l})$ & \\
\hline & Competição: & Competição: & \\
\hline & Homens: $22.1 \mathrm{nmol} / 1$ / Mulheres: $29.0 \mathrm{nmol} / 1$ & Homens $(22.1 \mathrm{nmol} / \mathrm{l}) /$ Mulheres $(29.0 \mathrm{nmol} / \mathrm{l})$ & \\
\hline \multirow{4}{*}{$\begin{array}{l}\text { Filaire et al. } \\
\quad(2010)\end{array}$} & Repouso: Basal (12.2 nmol/l) & Repouso: Basal (12.2 nmol/l) & \multirow{4}{*}{$\begin{array}{c}\text { Dia do jogo: } \uparrow 52 \% \\
10 \text { minutos antes do jogo: } \uparrow 99 \% \\
10 \text { minutos após o jogo: } \uparrow 141 \%\end{array}$} \\
\hline & Dia do jogo: Basal (18.5 nmol/l), & Dia do jogo: Basal (18.5 nmol/l), & \\
\hline & 10 minutos antes $(24.3 \mathrm{nmol} / \mathrm{l})$ & 10 minutos antes $(24.3 \mathrm{nmol} / \mathrm{l})$ & \\
\hline & 10 minutos após (29.4 nmol/l) & 10 minutos após (29.4 nmol/l) & \\
\hline
\end{tabular}

Nota: $\uparrow=$ Aumento nas concentrações de cortisol 
Tabela 4

Diferenças percentuais nas concentrações de cortisol sanguíneo encontradas para atletas

\begin{tabular}{|c|c|c|c|}
\hline Artigos & Valores encontrados & Valores corrigidos $(\mathrm{nmol} / \mathrm{l})$ & $\begin{array}{l}\text { Diferença percentual nas concentrações de } \\
\text { cortisol sanguíneo }\end{array}$ \\
\hline \multirow{3}{*}{$\begin{array}{l}\text { Teixeira et al. } \\
\text { (2009) }\end{array}$} & T1 (primeira temporada): $223 \mathrm{nmol} / 1$ & $\mathrm{~T} 1: 223 \mathrm{nmol} / \mathrm{l}$ & \multirow{3}{*}{$\begin{array}{c}\text { T1 vs T2: } \downarrow 15.7 \% \\
\text { T2 vs T3: } \downarrow 12.2 \%\end{array}$} \\
\hline & T2 (temporada pré-competitiva): $188 \mathrm{nmol} / 1$ & $\mathrm{~T} 2: 188 \mathrm{nmol} / \mathrm{l}$ & \\
\hline & T3 (temporada competitiva): $165 \mathrm{nmol} / 1$ & T3: $165 \mathrm{nmol} / \mathrm{l}$ & \\
\hline \multirow{5}{*}{$\begin{array}{l}\text { Salvador et al. } \\
\qquad(2001)\end{array}$} & Homens & Homens & \multirow{3}{*}{$\begin{array}{c}\text { Homens: } \\
\text { Pós-treino: } \uparrow 14 \%\end{array}$} \\
\hline & Antes $(275.31 \mathrm{nmol} / \mathrm{l}) /$ & Antes $(275.31 \mathrm{nmol} / \mathrm{l}) /$ & \\
\hline & Após (315.86 nmol/1) & Após (315.86 nmol/l) & \\
\hline & Mulheres & Mulheres & Mulheres \\
\hline & $\begin{array}{l}\text { Antes }(207.58 \mathrm{nmol} / 1) / \\
\text { Após }(317.58 \mathrm{nmol} / \mathrm{l})\end{array}$ & $\begin{array}{l}\text { Antes }(207.58 \mathrm{nmol} / 1) / \\
\text { Após }(317.58 \mathrm{nmol} / \mathrm{l})\end{array}$ & Pós-treino: $\uparrow 53 \%$ \\
\hline \multirow{3}{*}{$\begin{array}{l}\text { Coutts et al. } \\
\quad(2007)\end{array}$} & Basal: IT $(652.8 \mathrm{nmol} / \mathrm{l}) /$ & Basal: IT $(652.8 \mathrm{nmol} / \mathrm{l}) /$ & \multirow{3}{*}{ Basal vs. Pós treino: IT $(\uparrow 0.3 \%) / \mathrm{TN}(\downarrow 4.4 \%)$} \\
\hline & $\mathrm{TN}(630.3 \mathrm{nmol} / \mathrm{l})$ & $\mathrm{TN}(630.3 \mathrm{nmol} / \mathrm{l})$ & \\
\hline & $\begin{array}{l}\text { Pós treino: IT }(654.9 \mathrm{nmol} / \mathrm{l}) / \\
\text { TN }(602.8 \mathrm{nmol} / \mathrm{l})\end{array}$ & $\begin{array}{c}\text { Pós treino: IT }(654.9 \mathrm{nmol} / \mathrm{l}) / \\
\text { TN }(602.8 \mathrm{nmol} / \mathrm{l})\end{array}$ & \\
\hline França et al. (2006) & $\begin{array}{l}\text { Antes da corrida (basal): } 20.3 \mu \mathrm{g} / \mathrm{dL} \\
\text { Final da corrida: } 42.5 \mu \mathrm{g} / \mathrm{dL}\end{array}$ & $\begin{array}{l}\text { Antes da corrida (basal): } 560 \mathrm{nmol} / 1 \\
\text { Final da corrida: } 1172.5 \mathrm{nmol} / 1\end{array}$ & Basal vs. Final da corrida: $\uparrow 109 \%$ \\
\hline \multirow{4}{*}{ Garcia et al. (2002) } & Coleta S0: $594.41 \mathrm{nmol} / 1$ & Coleta S0: $594.41 \mathrm{nmol} / 1$ & \multirow{4}{*}{$\begin{array}{c}\text { S0 vs. S1: } \downarrow 41 \% \\
\text { S0 vs. S2: } \downarrow 76 \% \\
\text { S0 vs. S3: } \downarrow 97 \%\end{array}$} \\
\hline & Coleta S1: $420.21 \mathrm{nmol} / 1$ & Coleta S1: $420.21 \mathrm{nmol} / 1$ & \\
\hline & Coleta S2: $337.97 \mathrm{nmol} / 1$ & Coleta S2: $337.97 \mathrm{nmol} / 1$ & \\
\hline & Coleta S3: $301.19 \mathrm{nmol} / 1$ & Coleta S3: $301.19 \mathrm{nmol} / 1$ & \\
\hline \multirow{3}{*}{ Silva et al. (2011) } & $\mathrm{T} 1$ (antes inicio programa treino): $442 \mathrm{nmol} / \mathrm{l}$ & $\mathrm{T} 1$ (antes inicio programa treino): $442 \mathrm{nmol} / 1$ & T1 vs. T2: $\uparrow 25 \%$ \\
\hline & T2 (durante período-semana seis): $554.6 \mathrm{nmol} / 1$ & T2 (durante período-semana seis): $554.6 \mathrm{nmol} / 1$ & T1 vs. T3: $\uparrow 38 \%$ \\
\hline & T3 (ao final do programa): $612.2 \mathrm{nmol} / 1$ & T3 (ao final do programa): $612.2 \mathrm{nmol} / \mathrm{l}$ & T2 vs. T3: $\uparrow 10 \%$ \\
\hline
\end{tabular}

Grupo de Treino Intensificado; TN: Grupo de Treino Normal; S0 (um dia antes da competição - repouso); S1 (no

(no final da terceira semana); $\uparrow=$ Aumento nas concentraç̃̃es de cortisol; $\downarrow$ = Diminuição nas concentrações de cortisol 
Tabela 5

Diferenças percentuais nas concentrações de cortisol urinário encontradas para atletas

\begin{tabular}{|c|c|c|c|}
\hline Artigo & Valores encontrados & Valores corrigidos (nmol/l) & $\begin{array}{c}\text { Diferença percentual nas concentrações de } \\
\text { cortisol sanguíneo }\end{array}$ \\
\hline \multirow{3}{*}{$\begin{array}{l}\text { Rouveix et al. } \\
\text { (2006) }\end{array}$} & Repouso: $36.8 \mathrm{nmol} / \mathrm{l}$ & Repouso: $36.8 \mathrm{nmol} / \mathrm{l}$ & \multirow{3}{*}{$\begin{array}{c}\uparrow 46 \% \text { e } 38 \% \text { após } 3 \text { meses e } 4 \text { meses de treino, } \\
\text { respetivamente. }\end{array}$} \\
\hline & $\begin{array}{l}\text { Após } 3 \text { meses de treino de resistência: } \\
\qquad 53.8 \mathrm{nmol} / 1\end{array}$ & $\begin{array}{l}\text { Após } 3 \text { meses de treino de resistência: } \\
\qquad 53.8 \mathrm{nmol} / 1\end{array}$ & \\
\hline & $\begin{array}{l}\text { Após } 4 \text { meses de treino normal: } \\
\qquad 50.7 \mathrm{nmol} / 1\end{array}$ & $\begin{array}{l}\text { Após } 4 \text { meses de treino normal: } \\
50.7 \mathrm{nmol} / 1\end{array}$ & \\
\hline
\end{tabular}


Apenas $4.5 \%$ das investigações procederam à coleta de cortisol em repouso em situação desportiva (França, Neto, Agresta, Lotufo \& Kater, 2006) e $4.5 \%$ realizou coleta basal apenas antes da situação desportiva (Jurimae, Maetsu, Purge \& Jurimae, 2004).

De entre os artigos que utilizaram o cortisol salivar como medida de análise, o percentual de aumento na comparação dos valores de cortisol basal nas condições pré e pós-treino ( $4.5 \%$ dos estudos) foi de $32 \%$. Nos estudos que realizaram as coletas em repouso no mesmo horário em que ocorreu a competição, o percentual de aumento das concentrações de cortisol salivar variou de $73 \%$ a $163 \%$ ao comparar a situação de repouso com as situações de competição. Nos estudos que compararam os valores de cortisol basal com os valores de competição, o percentual de aumento variou de $52 \%$ a $70 \%$. Nos estudos que compararam valores basais com valores pós-competição o percentual de aumento foi de $141 \%$ a $180 \%$.

Nos estudos que realizaram coletas em situações de treino (no início, durante e ao final do programa de treino), as concentrações de cortisol sanguíneo diminuíram em um dos estudos (entre $12.2 \%$ e $15.7 \%$ ) e aumentaram em outro (entre $10.4 \%$ e $38.2 \%$ ).

Quando as concentrações de cortisol sanguíneo foram comparadas entre as condições de repouso e as condições pré e pós-treino, foi observado um aumento de $14 \%$ nas concentrações de cortisol pré e pós-treino para os homens e de $53 \%$ para mulheres. Ao analisar os valores de cortisol basal com os valores póstreino, com diferentes intensidades (treino intenso e treino normal), foi encontrado um reduzido aumento $(0.3 \%)$ para o grupo de treino intenso e pequena diminuição $(4.4 \%)$ no grupo com treino normal. Quando as concentrações de cortisol sanguíneo foram avaliadas na situação de competição, observou-se aumento de $109 \%$ nas concentrações de cortisol quando foi comparado o valor basal com o valor após a competição (França et al., 2006). Contrariamente, quando foi avaliado um período competitivo (três semanas), constatou- se que os valores de cortisol diminuíram em torno de $41 \%$ na primeira semana, $76 \%$ na segunda semana e $97 \%$ na terceira semana, em relação aos valores encontrados no período pré-competitivo (Garcia et al., 2002). No caso do cortisol urinário, apenas um artigo $(4.5 \%$ dos estudos) apresentou resultados significativos, com aumento percentual de $46 \%$ entre os valores de repouso e após três meses de treino e $38 \%$ entre os valores de repouso e após quatro meses de treino.

\section{DISCUSSÃO}

O presente estudo revelou a predominância do cortisol salivar como medida de análise do estresse desportivo, possivelmente por este se constituir numa medida de mensuração eficaz, acessível, rápida e não invasiva. Além disso, este método possibilita que a coleta seja feita em qualquer situação, sem problemas de reatividade, nem constrangimentos práticos ou éticos comuns aos métodos de coleta de sangue e urina (Soares \& Alves, 2006).

Nos artigos revisados houve predominância de atletas de alto rendimento e em situações de competitividade. A competição tem sido caracterizada como uma situação em que o atleta se confronta com uma série de pressões que, de acordo com aspectos individuais e situacionais, podem gerar considerável fonte de estresse (Brandão, 2000; De Rose Jr, 2002). Além disso, Leme, Barberi, Curiacos e Rogatto (2008) mencionam que também a situação précompetitiva é geradora de estresse, podendo haver prejuízo no desempenho do atleta se não houver nenhuma interferência. É importante ressaltar que a situação de competição envolve a interação entre as demandas do meio (fatores de ordem externa relacionados ao ambiente competitivo) e os recursos pessoais dos atletas (fatores de ordem interna determinados pelo próprio indivíduo) (Brandão, 2000; De Rose Jr, 2002; Castro, 2008; Samulski \& Chagas, 1992). Assim, diante de qualquer estímulo estressor (físico e/ou psicológico) poderá haver reações psicofisiológicas que resultam em hiperfunção do sistema nervoso central e do 
sistema endócrino, mais particularmente da glândula suprarrenal, resultando na maior liberação de hormônios glucocorticoides como o cortisol (Brandão \& Lachat, 1995).

A maioria dos artigos contemplou atletas entre 19 e 29 anos, considerados adultos jovens (Havighurst \& Levine 1979), possivelmente devido a esta classificação etária ser dominante no âmbito desportivo, uma vez que a média de idades em que ocorre a profissionalização de atletas é algo curta (18.22 \pm 4.66 anos), assim como a duração da carreira desportiva (34.36 \pm 4.42 anos) (Agresta, 2006).

Constatou-se que a maioria dos artigos foi realizada com modalidades individuais. Considerando que a preparação e adaptação de atletas de desportos coletivos diferem muito daquelas executadas em modalidades individuais, Gamble (2006) cita que um aspeto importante a ser levado em conta é a ampla diversidade de habilidades técnicas e táticas que precisam ser trabalhadas, somadas à preparação física que muitas vezes exige o treino de mais de uma capacidade ao mesmo tempo (força máxima, potência, resistência, capacidade aeróbia, agilidade, entre outras). Todos esses objetivos necessitam de uma adaptação fisiológica específica que muitas vezes não são compatíveis entre os atletas, causando conflitos. Nesse sentido, acredita-se que a maioria dos estudos da presente revisão comtemplou modalidades individuais buscando excluir estes conflitos dos seus resultados.

Verificou-se também maior incidência de estudos com atletas masculinos (59\%), em comparação aos femininos (13.7\%), embora $27.3 \%$ dos artigos tenham contemplado amostras mistas. Esta prevalência pode ser explicada pelo fato da participação da mulher no desporto ser recente. Somente nos últimos anos, a mulher passou a ser foco de pesquisas no cenário desportivo (Devide et al., 2011). Além disso, as pesquisas envolvendo aspetos anatómicos, psicológicos e hormonais, que comprometem a performance da mulher desportista, têm sido restritas. Contudo, alguns estudos (Kivlighan, Douglas \& Booth, 2005; Segato, Brandt,
Liz, Vasconcellos, \& Andrade, 2010; Teixeira et al., 2009) que compararam as concentrações de cortisol entre homens e mulheres não evidenciaram diferenças nas variações de cortisol entre os géneros. Além disso, não se têm encontrado diferenças nas concentrações de cortisol sanguíneo, realizadas pela manhã a cada 2-3 dias, considerando o ciclo menstrual das mulheres (Monti-Bloch, Jennings-White, \& Berliner, 1998). Estes achados são corroborados por Abplanalp, Livingston, Rose e Sandwisch (1977), que evidenciaram que o cortisol não sofre mudanças significativas em função das fases menstrual e intermenstrual.

Os artigos revisados que realizaram coletas em situação de repouso e/ou basais, a fim de controlar o ciclo circadiano do cortisol, apresentaram grande diversidade nos procedimentos para a análise do cortisol nos demais períodos de coleta (durante e após o treino, antes e após a competição), demonstrando ausência de um único protocolo para a avaliação do estresse desportivo. Destaca-se, contudo, que o ciclo circadiano, presente em todos os seres humanos, normalmente, é sincronizado com o dia solar, garantindo que vigilância e pico de desempenho ocorram na vigília (durante o dia) e o sono durante a noite (Gooley, 2008). Desse modo, a comparação das concentrações de cortisol em condições basais/repouso com aquelas encontradas em situações desportivas foi evidenciada em alguns dos estudos revisados, a fim de se reconhecer o efeito de um evento potencialmente estressante sobre a secreção desse hormônio. Mesmo que dois ou mais atletas apresentem valores similares de cortisol em situações desportivas, não há como inferir que estes valores são, exclusivamente, devidos ao estresse desportivo, se não forem controlados os valores basais/repouso. Apesar de uma situação poder ser geradora de estresse para um atleta e não para outro (dependendo da demanda física e psicológica), os estudos revisados nem sempre descreveram as situações e/ou momentos da coleta de dados, o que dificulta o entendimento dos resultados e a comparação entre eles. 
As alterações nas concentrações de cortisol salivar encontradas nos artigos revisados evidenciaram que muitas das situações desportivas estudadas (competição e treino) podem ser consideradas potenciais fontes de estresse para atletas de diferentes modalidades e níveis competitivos. Os mais elevados percentuais de aumento nas concentrações de cortisol foram encontrados entre a situação basal e a situação pós-competitiva (Filaire et al., 2010; França et al., 2006), bem como entre as coletas realizadas no dia da competição e aquelas mensuradas no mesmo horário em repouso (Maso et al., 2003). Uma das possíveis explicações para esses achados é que a produção e a secreção do cortisol aumentam durante e após a exposição do indivíduo às situações que sejam consideradas estressoras, sejam estas de ordem física ou psicológica (Kim et al., 2009; Soares \& Alves, 2006). No caso dos artigos revisados, a demanda física foi o fator que mais esteve associado com o aumento das concentrações de cortisol. Alguns autores têm enfatizado que as variações nas concentrações de cortisol são dependentes da ativação dos parâmetros fisiológicos, como a intensidade e a duração dos exercícios (Filaire et al., 2001; Kanaley, Weltman, Pieper, Weltman, \& Hartman, 2001). Desse modo, parece plausível que intensidades elevadas de esforço físico e psíquico sejam fundamentais para se diagnosticarem elevações na secreção de cortisol (Acevedo et al., 2007).

No caso do cortisol sanguíneo, a diversidade metodológica dos estudos revisados levou a resultados distintos, inviabilizando a comparação das concentrações de cortisol encontradas. No artigo que buscou investigar os efeitos longitudinais do treino físico intenso (Teixeira et al., 2009), destaca-se que houve diminuição nas concentrações de cortisol obtidas entre as temporadas avaliadas, o que pode ser atribuída à adaptação dos atletas às temporadas de treino, facto este que também pôde ser observado em um período de três semanas de competição (Fernández-Garcia et al., 2002).

Referente às limitações dos artigos revisados, destacam-se: (a) o reduzido número de participantes que compuseram a amostra pesquisada (Filaire et al., 2010; Salvador et al., 2003; Strahler et al., 2010), (b) a amostra ser composta quase exclusivamente por homens; (c) a falta de utilização de outros marcadores fisiológicos para avaliar o estresse (Mineto et al., 2008; Strahler et al., 2010); (d) as análises hormonais terem sido restritas a um único período (manhã ou tarde), não abrangendo todo o ciclo de $24 \mathrm{~h}$, o que não permite estimar o ciclo circadiano; e (e) o estado de saúde de todos os participantes ser considerado apenas através de autorrelato (Strahler, 2010).

No presente estudo de revisão, a falta de padronização entre os procedimentos de coleta para avaliar as concentrações de cortisol sanguíneo, urinário e salivar foi a principal limitação encontrada entre os artigos revisados, o que dificultou a comparação dos resultados obtidos.

\section{CONCLUSÕES}

No presente estudo de revisão, constatou-se grande diversidade de modalidades desportivas, sendo a maioria dos estudos realizada com modalidades individuais, com atletas do género masculino e com atletas profissionais de alto rendimento. Observou-se também predominância de estudos que utilizaram o cortisol salivar como medida de análise do estresse desportivo, possivelmente pelo fato do cortisol salivar ser menos invasivo, em comparação com o sanguíneo e o urinário.

A ausência de um único protocolo para a avaliação do estresse desportivo dificulta a comparação dos resultados encontrados e a identificação de valores de referência, ainda desconhecidos. No entanto, os percentuais mais elevados foram encontrados quando se compararam as concentrações de cortisol na situação basal com a situação pós-competitiva. Nos estudos que compararam valores basais com valores pós-competição o percentual de aumento chegou a $180 \%$. Da mesma forma, quando confrontadas as medidas de cortisol realizadas no dia da competição e aquelas mensuradas no mesmo horário em situação de 
repouso, existiu uma variação percentual de $73 \%$ a $163 \%$.

Além disso, os artigos revisados apontaram importantes variáveis associadas à dinâmica desportiva que interferem na avaliação do estresse, tais como: período das coletas nas situações de treino e competição (antes, durante e após); e, variáveis psicológicas (ansiedade; autoconfiança), esforço físico despendido e desempenho.

Nesse sentido, fica clara a necessidade de se ampliar as pesquisas com medidas objetivas do estresse desportivo, que esclareçam os procedimentos utilizados para a coleta de dados, bem como suas limitações, a fim de permitir a padronização nos métodos de análise do cortisol em atletas e encontrar valores referenciais.

\section{Agradecimentos:}

Nada a declarar.

Conflito de Interesses:

Nada a declarar.

Financiamento:

Nada a declarar.

\section{REFERÊNCIAS}

Abplanalp, J. M., Livingston, L., Rose, R. M., \& Sandwisch, D. (1977). Cortisol and growth hormone responses to psychological stress during the menstrual cycle. Psychosomatic Medicine, 39(3), 158-177.

Acevedo, E. O., Kraemer, R. R., Kamimori, G. H., Durand, R. J., Johnson, L. G., \& Castracane, V. D. (2007). Stress hormones, effort sense, and perceptions of stress during incremental exercise: An exploratory investigation. Journal of Strength and Conditioning Research, 21(1), 283288.

Agresta, M. C. (2006). Causas e conseqüências do término de carreira esportiva em jogadores brasileiros de basquetebol e futebol profissional. Dissertação de Mestrado, Universidade Federal de São Paulo, Brasil.
Aubets, J., \& Segura, J. (1995). Salivary cortisol as a marker of competition related stress. Science and Sports, 10(3), 149-154. doi: 10.1016/07651597(96) 89361-0

Atlaqui, D., Duclos, M., Gouarne, C., Lacoste, L., Barale, F., \& Chatard, J. C. (2004). The 24-h urinary cortisol/cortisone ratio for monitoring training in elite swimmers. Medicine \& Science in Sports \& Exercise, 36(2), 218-224. doi: 10.1249/ 01.MSS.0000113481.03944.06

Bought, M., Rouveix, M., Michaux, O., Pequignot, J., \& Filaire, E. (2006). Relationships among training stress, mood and dehydroepiandrosterone sulphate/cortisol ratio in female cyclists. Journal of Sports Sciences, 24(12), 12971302. doi: 10.1080/02640410500497790

Brandão, M. L, \& Lachat, J. (1995). Noções básicas de neuroanatomia. In M. L. Brandão (Ed.), Psicofisiologia (pp. 1-17). São Paulo: Atheneu.

Brandão, M. R. F. (2000). Fatores de stress em jogadores de futebol profissional. Tese de Doutorado, Universidade Estadual de Campinas, Brasil.

Bullock, N., Cox, A. J., Martin, D. T., \& Marino, F. E. (2009). Resting salivary and plasma cortisol in elite athletes following long-haul travel from Australia to Canada. Journal of Science and Medicine in Sport, 12(2), 300-302. doi: 10.1016/ j.jsams.2007.11.004

Castro, M. V. (2008). Análise das situações competitivas desencadeadoras de estresse em atletas escolares de basquetebol. Dissertação de Mestrado, Universidade de Brasília, Brasil.

Coutts, A. J., Wallace, L. K., \& Slattery, K. M. (2007). Monitoring changes in performance, physiology, biochemistry, and psychology during overreaching and recovery in triathletes. International Journal Sports and Medicine, 28, 125134. doi: 10.1055/s-2006-924146

Cormack, J. S., Newton, R. U., Mcguigan, R. M., \& Cormie, P. (2008). Neuromuscular and endocrine responses of elite players during an Australian rules football season. International Journal of Sports Physiology and Performance, 3, 439-453.

David, A. M., Di Bella, Z., Berenstein, E., Lopes, A., \& Vaisberg, M. (2009). Incidência da sindrome pré-menstrual na prática de esportes. Revista Brasileira de Medicina do Esporte, 15, 330-333. doi: 10.1590/S1517-86922009000600001

De Rose Jr, D. (2002). A competição como fonte de estresse no esporte. Revista Brasileira de Ciência e Movimento, 10(4), 19-26. 
Devide, F. P., Osborne, R., Silva, E. R., Ferreira, R. C., Clair, E. S., \& Nery, L. C. (2011). Estudos de gênero na Educação Física Brasileira. Motriz. Revista da Educação Física, 7(1), 93-103. doi: 10.5016/1980-6574.2011v17n1p93

Fernández-Garcia, B., Lucía, A., Hoyos, J., Chicharro, J. L., Rodriguez-Alonso, M., Bandrés, F., \& Terrados, N. (2002). The response of sexual and stress hormones of male pro-cyclists during continuous intense competition. International Journal of Sports Medicine, 23(8), 555-560. doi: 10.1055/s-2002-35532

Filaire, E., Alix, D., Ferrand, C., \& Verger, M. (2009). Psychophysiological stress in tennis players during the first single match of a tournament. Psychoneuroendocrinology, 34, 150-157. doi: 10.1016/j.psyneuen.2008.08.022

Filaire, E., Portier, H., Onen, N., \& Filaire, M. (2010). Physiological responses and nutritional profile during competitive female singles tennis. Science \& Sports, 25(2), 55-60. doi: 10.1016/j.scispo.2009.11.001

Filaire, E., Sagnol, M., Ferrand, C., Maso, F., \& Lac, G. (2001). Psychophysiological stress in judo athletes during competitions. The Journal of Sports Medicine and Physical Fitness, 41(2), 263268.

Filin, V. (1996). Desporto Juvenil: teoria e metodologia. Londrina: CID.

França, S., Barros Neto, T., Agresta, M., Lotufo, R., \& Kater, C. (2006). Resposta divergente da testosterona e do cortisol séricos em atletas masculinos após uma corrida de maratona. Arquivos Brasileiros de Endocrinologia \& Metabologia, 50, 1082-1087.

Gamble, P. (2006). Periodization of training for team sports athletes. Strength and Conditioning Journal, 28 (5), 56-66. doi: 10.1519/1533-4295

Garcia, B. F., Lucía, A., Hoyos, J., Chicharro, J. L., Alonso, M. R., Bandrés, F., \& Terrados, N. (2002). The response of sexual and stress hormones of male pro-cyclists during continuous intense competition. International Journal Sports and Medicine, 23, 555-560. doi: 10.1055/s-200235532

Georgopoulos, N. A., Rottstein, L., Tsekouras, A., Theodoropoulou, A., Koukkou, E., Mylonas, P., ... Markou, A. K. (2011). Abolished circadian rhythm of salivary cortisol in elite artistic gymnasts. Steroids, 76, 353-357. doi: 10.1016/ j.steroids.2010.10.013
Goellner, S. V. (2005). Mulher e esporte no Brasil: Entre incentivos e interdições elas fazem história. Pensar a Prática - UFG, 8(1), 85-100. doi: 10.5216/rpp.v8i1.106

Gooley, J. J. (2008). Treatment of circadian rhythm sleep disorders with light. Annals of the Academy of Medicine Singapore, 37(8), 669-676.

Havighurst, R., \& Levine, R. (1979). Society and Education. Boston: Allyn \& Bacon.

Hofstra, W. A., \& De Weerd, A. W. (2008). How to assess circadian rhythm in humans: A review of literature. Epilepsy and Behavior, 13(3), 438-444. doi: 10.1016/j.yebeh.2008.06.002

Houston, M. E. (2001). Bioquímica básica da ciência do exercício. São Paulo: Roca.

Jurimae, J., Maetsu, J., Purge, P., \& Jurimae, T. (2004). Changes in stress and recovery after heavy training in rowers. Journal of Science and Medicine in Sport, 7(3), 334-339.

Kanaley, J. A., Weltman, J. Y., Pieper, K. S., Weltman, A., \& Hartman, M. L. (2001). Cortisol and growth hormone responses to exercise at different times of day. Journal of Clinical Endocrinology and Metabolism, 86(6), 2881-2889. doi: 10.1210/jc.86.6.2881

Kim, K. J., Chung, J. W., Park, S., \& Shin, J. T. (2009). Psychophysiological stress response during competition between elite and non-elite Korean junior golfers. International Journal of Sports Medicine, 30(7), 503-508. doi: 10.1055/s0029-1202338

Kivlighan, K. T., Granger, D., \& Booth, A. (2005). Gender differences in testosterone and cortisol response to competition. Psychoneuroendocrinology, 30(1), 58-71. doi: 10.1016/j.psyneuen. 2004.05.009

Leme, J. A., Barberi, R. A., Curiacos, K. J., \& Rogatto, P. (2008). Influência do alongamento no estresse pré-competitivo em jogadores de futebol da categoria juvenil. Motricidade, 4(3), 57-60. doi: 10.6063/motricidade.4(3).271

Maestu, J., Jurimae, J., \& Jurimae, T. (2003). Hormonal reactions during heavy training stress and following tapering in highly trained male rowers. Hormone and Metabolic Research, 35, 109113. doi: $10.1055 / \mathrm{s}-2003-39053$

Maso, F., Cazorla, G., Godemet, M. O., Michaux A. G., Lac, A., \& Robert, A. (2002). Influence d'une compétition de rugby sur le taux de cortisol salivaire. Science et Sports 17(6), 302-305.

Maso, F., Lac, G., Michaux, O., \& Robert, A. (2003). Corrélations entre scores au questionnaire de 
la Société française de médecine du sport et concentrations de cortisol et testostérone salivaires lors du suivi d'une équipe de rugby de haut niveau. Science \& Sports, 18, 299-301. doi: 10.1016/j.scispo.2003.09.012

Minetto, M. A., Lanfranco, F., Tibaudi, A., Baldi, M., Termine, A., \& Ghigo, E. (2008). Changes in awakening cortisol response and midnight salivary cortisol are sensitive markers of strenous training-induced fatigue. Journal of Endocrinological Investigation, 31, 16-24.

Monti-Bloch, L., Jennings-White, C., \& Berliner, D. L. (1998) The human vomeronasal system: A review. Annals of the New York Academy of Sciences, 855, 373-389.

Nahas, M. V. (2001). Atividade física, Saúde e Qualidade de Vida: Conceitos e Sugestões para um Estilo de Vida Ativo. Londrina: Midiograf.

Salvador, A., Ricarte, J., González-Bono, E., \& MoyaAlbiol, L. (2001). Effects of physical training on endocrine and autonomic response to acute stress. Journal of Psychophysiology, 15, 114-121. doi: 10.1027//0269-8803.15.2.114

Salvador, A., Suay, F., González-Bono, E., \& Serrano, M. A. (2003). Anticipatory cortisol, testosterone and psychological responses to judo competition in young men. Psychoneuroendocrinology, 28, 364-375. doi: 10.1016/s03064530(02)00028-8

Sampaio, R. F., \& Mancini, M. C. (2007). Estudos de revisão sistemática: Um guia para síntese criteriosa da evidência científica. Revista Brasileira de Fisioterapia, 11, 83-89.

Samulski, D., \& Chagas, M. H. (1992). Análise do stress psíquico na competiçäo em jogadores de futebol de campo das categorias infantil e juvenil (15-18 anos). Revista Brasileira de Ciência e Movimento, 6(4), 12-18.

Segato, L., Brandt, R., Liz, C. M., Vasconcellos, D. I. C., \& Andrade, A.(2010). Estresse psicológico de velejadores de alto nível esportivo em competição. Motricidade, 6(3), 53-62. doi: 10.6063/motricidade.6(3).145

Silva, A. S., Papoti, M., Santhiago, V., Pauli, J. R., \& Gobatto, C. A. (2011). Serum and plasma hormonal concentrations are sensitive to periods of intensity and volume of soccer training. Science \& Sports, 26, 278-285. doi: 10.1016/ j.scispo.2010.12.006

Soares, A. J., \& Alves, M. G. (2006). Cortisol como variável em psicologia da saúde. Psicologia, Saúde e Doenças, 7(2), 165-177.

Strahler, K., Ehrlenspiel, F., Heene, M., \& Ralf, B. (2010). Competitive anxiety and cortisol awakening response in the week leading up to a competition. Psychology of Sport and Exercise, 11, 148-154. doi:10.1016/j.psychsport.2009.10.003 Suay, F., Salvador, A., González-Bono, E., Sanchís, C., Martínez, M., Martínez-Sanchis, S., ... Montoro, J. B. (1999). Effects of competition and its outcome on serum testosterone, cortisol and prolactin. Psychoneuroendocrinology, 24(5), 551566. doi: 10.1016/s0306-4530(99) 00011-6.

Rouveix, M., Duclos, M., Gouarne, C., Beauvieux, M. C., \& Filaire, E. (2006). The 24 h urinary cortisol/cortisone ratio and epineprine/norepinephrine ratio for monitoring training in young female tennis players. International Journal Sports and Medicine, 27, 856-863. doi: 10.1055/s-2006-923778

Teixeira, V., Valente, H., Casal, S., Pereira, L., Marques, F., \& Moreira, P. (2009). Antioxidant status, oxidative stress, and damage in elite kayakers after 1 year of training and competition in 2 seasons. Applied Physiology, Nutrition and Metabolism, 34, 716-724. doi: 10.1139/h09062

Wilmore, E. J., \& Costill, D. (2003). Fisiologia do Esporte e do Exercício (1 ${ }^{\mathrm{a}}$ ed.). São Paulo: Manole. quando especificado em contrário e nos conteúdos retirados de outras fontes bibliográficas. 